\title{
Developing a List of Compensable Occupational Diseases: Principles and Issues
}

\author{
Tim Driscoll*, ${ }^{*}$, Mark Wagstaffe ${ }^{2}$ and Neil Pearce ${ }^{2}$ \\ ${ }^{I}$ Sydney School of Public Health, University of Sydney, Australia \\ ${ }^{2}$ Centre for Public Health Research, Massey University, New Zealand
}

\begin{abstract}
Background: A number of countries have a list of occupational disorders for use in workers' compensation processes and decisions. These lists have two potential uses - to formally recognise that a disorder may be related to work (and so be potentially compensable), or to formally identify disorders that are likely to be related to work and so can be considered to have arisen from work if sufficient relevant exposure can be confirmed. However, many of these lists have shortcomings.

Objectives: The aim of this paper is to provide an overview of the concepts and approaches that should be taken into account when developing a list of occupational disorders that can be accepted for fast tracking of the compensation claim.

Results and Conclusions: A list of occupational disorders to be used as a schedule for compensation purposes is best based on a combination of specific disorder-exposure combinations, unless the number of potential exposures linked to a particular disorder, or the number of disorders linked to a particular exposure, make it impractical to list them all. For inclusion in a schedule it is desirable that there is strong evidence of causal link between the occupational exposure and the disorder; there are clear and repeatable criteria for diagnosing the disorder; and the disorder comprises a considerable proportion of the cases of that disorder in the overall population or an identifiable subset of the population.
\end{abstract}

Keywords: Occupational, compensation, criteria, ILO.

\section{INTRODUCTION}

The International Labour Organization's List of Occupational Diseases (the ILO List) is documented in ILO Convention 42 (Workmen's Compensation (Occupational Diseases) Convention (Revised), 1934). This has been revised several times since it was first released, most recently at a meeting in late 2009, with ratification expected in 2010 [1]. A number of countries have their own equivalent of this list, almost always based heavily on the ILO List, which is used to guide workers' compensation processes and decisions. Many examples are available - e.g. lists from Europe [2], Hong Kong [3], Germany [4], Ireland [5], Ontario (Canada) [6], the Phillipines [7] and South Africa [8]. These lists have two potential uses - to formally recognise that a disorder may be related to work (and so be potentially compensable), or to formally identify disorders that are likely to be related to work and so can be considered to have arisen from work if sufficient relevant exposure can be confirmed (this latter commonly referred to as a disease schedule). Such lists are potentially very useful for both workers and public authorities. However, many of them have shortcomings, particularly when used for the second of these purposes. Some of the issues relevant to the development of such lists for the first use are considered in a document produced to support the development of the most recent version of the ILO List [9].

*Address correspondence to this author at the Sydney School of Public Health, Edward Ford Building (A27), University of Sydney NSW 2006, Australia; Tel: 61-2-9351 4372; Fax: 61-2-9351 7420;

E-mail: Tim.Driscoll@sydney.edu.au
The focus of the current paper is the second of the abovementioned uses.

Schedule 2 of the New Zealand Injury Prevention, Rehabilitation and Compensation Act 2001 provides a list of occupational disorders and exposures. Claims made for disorders and exposures contained within Schedule 2 of the Act are able to be considered more quickly than other claims because the connection between the disorder and an occupational exposure is automatically accepted. The content of Schedule 2 was recently reviewed. The aim of this paper is to provide an overview of the concepts and approaches that should be taken into account when developing a list of accepted occupational disorders, using recent experience with New Zealand's Schedule 2 to illustrate some of the principles and issues involved.

\section{PRINCIPLES AND ISSUES}

Schedules are designed to provide a list of disorders for which there is very good evidence of a causal connection to one or more workplace exposures. Disorders listed on such a schedule are accepted as arising from work, provided that the claimant has experienced the relevant exposure in the course of work, and can be handled using a fast-track process. Disorders not listed on the schedule may still be the subject of a workers' compensation claim, but the connection to work will need to be established as part of the claim process. Disorders potentially related to work may not be listed on a schedule for two main reasons. For many disorders, the level of scientific evidence of a causal connection to work is insufficient to allow a connection to work to be automatically accepted. For others, the proportion of cases due to work is 
so low that it is likely that in any individual, even if they are a worker with relevant work exposures, the disorder arose as a result of non-work exposures.

Most occupational disease schedules appear not to be based on clear, appropriate criteria and/or do not include all relevant disorders. For example, a comparison of the latest ILO List and the previous version of New Zealand's Schedule 2 showed that many of the categories listed in the ILO List were not included in Schedule 2. Even the ILO List does not include some disorders that can definitely arise due to occupational exposures, although the list currently being considered for adoption as an amendment to ILO Recommendation 194 is more comprehensive [1], and ILO Recommendation 194 recommends that countries include as many as possible of the disorders in the ILO List in their list of diseases that should be the basis for compensation. Although the ILO-listed disorders form a good starting point for establishing a comprehensive list of occupational disorders for use in a schedule, it is argued that they should not be adopted without modification, because they do not necessarily meet the appropriate criteria for a valid and practical occupational disease schedule. Three such criteria are proposed.

The first criterion is that there must be strong scientific evidence of a causal link between the disorder and one or more occupational exposures. This is essential, since the aim of a schedule is to by-pass the need for a claimant to establish a connection between a work-related exposure and a resulting disorder. A vast range of work-related exposures have been implicated in single studies as possibly resulting in ill health. However, many of these findings have not been repeated in other studies, or are only identified in studies with significant methodological flaws. For these, the evidence of a connection to work is weak. Inclusion of every disorder that has ever been linked to a work-related exposure would mean the acceptance of claims for a large number of conditions that are in fact not related to work or unlikely to be related to work. This would mean the schedule would not be suited to its main purpose. For other disorders, there is strong scientific evidence in terms of several well-conducted studies identifying a meaningfully-increased risk of developing the disorder in exposed persons compared to unexposed persons. These are the conditions that might appropriately be included in the Schedule. Therefore, one criterion for inclusion in a schedule should be that there is strong scientific evidence of a connection between the disorder and one or more work-related exposures.

The second criterion is that disorders included in a schedule must have clear diagnostic criteria. This will mean there should be little question as to whether or not the claimant really has the disorder that is the subject of the claim. For many of the potential disorders that could be included, the diagnostic criteria are straightforward. This is the case for virtually all malignancies and for most pneumoconioses, for example. The issue is less clear for conditions such as asthma, as there are several definitions of occupational asthma, some more inclusive than others [10-12]. Also, establishing the connection to work can be difficult, and might need to involve serial tests of lung function during a working week and during times away from work, as well as challenge tests. Some of the musculoskeletal disorders, such as those associated with upper limb pain $[13,14]$, and chronic neuropsychiatric disorders associated with solvent exposure [15, 16], are examples of disorders where establishing the diagnosis can be even more problematic. In many cases, there is lack of agreement as to what constitutes the disorder and on what basis it should be diagnosed. This is likely to mean that the diagnosis will often need to be made or confirmed by an occupational physician or a medical practitioner with considerable experience in occupational medicine.

The third criterion is that it is important that the disorder comprises a considerable proportion of the cases of that disorder in the overall population or in an identifiable subset of the population. In theory, a schedule should contain a list of every work-related disorder and its associated exposure. Unfortunately, most work-related disorders can also be caused by non-work exposures. Including every possible workrelated disorder, no matter how common or what proportion of all occurrences of the disorder are related to work, would make the schedule unwieldy and of little practical use. A response might be to only list disorders that are primarily caused by exposures that occur through work; that is, disorders where the occupational Population Attributable Fraction (essentially the proportion of cases of a particular disorder that is due to the exposure in question) is high. However, such an approach has important and undesirable implications. For example, the most common cause of lung cancer in the community is smoking. Lung cancer is also known to be caused by exposure to asbestos, and the most common circumstance in which asbestos exposure occurs is through work. If lung cancer is excluded from consideration because the primary cause is non-occupational, many people whose cancer is actually caused by occupational exposure to asbestos will find it much more difficult to receive compensation for their illness. Similarly, it has been reliably estimated that at least $10 \%$ to $15 \%$ of asthma $[10,17,18]$ in adults in industrialised countries is due to occupational exposures. This means that the other $85 \%$ to $90 \%$ of asthma cases are not due to occupational causes. Asthma is a common disease in most communities. Deciding not to include asthma on a schedule simply because most cases are not occupational in causation would potentially exclude a large number of cases that genuinely arose as a result of occupational exposures.

In applying this criterion, it is important to bear in mind that the proportion of cases of a particular disorder that are due to work will vary considerably between groups within the general population. A disorder that at a general population level is overwhelmingly non-occupational in origin might be primarily of occupational origin in certain subgroups where workers commonly have exposures that increase the risk of developing the disorder. Therefore, a disorder that is usually due to non-occupational factors, but commonly due to occupation in workers with a specific exposure, could reasonably be included in a schedule if it is directly linked to that exposure. For example, cases of tuberculosis would usually not be caused by occupational exposures, but tuberculosis in a health care worker is much more likely to be due to exposure to the causative organism as a result of work activities. So, tuberculosis in general would not be expected to be included in a schedule, but tuberculosis in health care workers might be. Similarly, bladder cancer diagnosed in a worker with known exposure to a bladder carcinogen is much more likely to be due to an occupational 
exposure than a bladder cancer diagnosed in someone who has always been a clerical worker.

\section{STRUCTURE AND CONTENT OF A SCHEDULE}

In general, a schedule should identify specific disorders in relation to one or more specific exposures. The current version of the ILO List of Diseases (and the Annex to the List), and most country-specific schedules, are a mixture of specific and non-specific disorders. An example of a specific disorder from Schedule 2 in New Zealand is "Lung cancer or mesothelioma diagnosed as caused by asbestos". It is usually straightforward to diagnose a person as having mesothelioma, and asbestos is virtually the only known cause of mesothelioma. It is also usually straightforward to diagnose a person as having lung cancer, although it is not possible to unequivocally establish whether or not an individual case of lung cancer arose as a result of asbestos exposure (or any other exposure).

Most of the other disorders listed in Schedule 2, and many of the disorders in the ILO List, are non-specific. For example, the ILO List includes "Diseases of a type generally accepted by the medical profession as caused by chrome or its toxic compounds". Chromium and related compounds are associated with lung cancer, dermatitis, skin ulcers, perforation of the nasal septum, respiratory tract irritation, and chronic renal failure [19]. All of these disorders can be caused by exposures other than chromium. It is not useful for a schedule to include, for example, all cases of dermatitis. Instead, the focus should be on dermatitis caused by exposure to chromium or its compounds. Therefore, a schedule is probably better structured primarily around the disorder, with qualifications as to what exposures should be considered as causal, rather than being structured around a particular exposure. So, "Diseases of a type generally accepted by the medical profession as caused by chrome or its toxic compounds" would be better along the lines of "Lung cancer associated with occupational exposure to: asbestos, chromium, coke oven emissions..."; "Chronic renal failure associated with occupational exposure to: lead, cadmium, chromium, copper...", and so on. The Annex to the ILO List adopts this approach in some situations. For example, "Asthma caused by recognized sensitizing agents or irritants inherent to the work process" focuses on the disorder (asthma) and identifies the need that the causative exposure occurs in relation to work.

Some variation in this focus on disorders is required in certain circumstances. When the exposure can be clearly related to work but there are many individual disorders and types of organ dysfunction that have been shown to be related to the exposure, the specific exposure should be included, accompanied by a general reference to the many disorders that might be related to it. This is the approach recommended for most cases of acute or chronic poisoning. Asthma illustrates a related issue, in that there are probably hundreds of occupational exposures that could potentially cause asthma [20]. So, it would not be practical to explicitly include them all in a schedule. This would also be the case for dermatitis [21]. In contrast, it might be well be feasible and appropriate to include in a list specific exposures that have been associated with a particular form of cancer.
For some disorders, connection to an occupation or industry, rather than exposure to a specific agent, may be necessary, but it is best avoided in most instances. Such connection is appropriate in two situations. Firstly, there may be very good evidence that work in a particular occupation or industry increases the risk of developing a specific disorder, but the specific agent has not been identified. An example of this is lung cancer and bladder cancer associated with work as a painter [22, 23]. The International Agency for Research on Cancer (IARC) lists a number of occupational exposure circumstances that are classified as definitely increasing the risk of cancer without definitively identifying the causative exposure(s) [22]. A single IARC exposure circumstance covers a range of different tasks and associated exposures, only some of which may be carcinogenic. Therefore, many of the people included in the exposure circumstance will actually not have been exposed to whatever the causative exposure (or exposures) was. As long as the relevant exposure is included in the schedule, it is not necessary to include the exposure circumstance as well. If the exposure is not well characterised and the disorder is common in the general public, the circumstance is better excluded from the schedule because it is too difficult to establish that a worker has been exposed to a truly causative exposure.

Secondly, for most infections related to occupation, the infection is inextricably linked to exposure to a single agent - the infective organism. That is, there is a clear one-to-one relationship between the disorder and an exposure. So, for infections uncommon in the general public, it makes more sense to identify the occupational circumstances in which exposure to the infective organism can be expected to occur, rather than to simply identify the infective organism, because identifying the infective organism doesn't add any extra information. For example, leptospirosis is more usefully linked to dairy farming and abattoir work than to exposure to Leptospira, the causative exposure.

For the majority of disorders in a community, most of the cases will arise from non-occupational exposure circumstances, but occupationally-related cases will arise sporadically. For example, a government worker in a temperate country might go to a tropical country for a brief work project and contract malaria, but it is not feasible to include every specific infection that might conceivably arise due to occupational exposure circumstances. Similar situations arise with disorders of all organ systems, such as heart failure, kidney disease, neurological disorders and haematological disorders. Therefore, these either need to be dealt with by including a "catch-all" provision in the schedule, or by accepting that such rare cases need to be dealt with through the compensation mechanisms that do not involve referral to a schedule. The latest version of the ILO List does include some catch-all categories, but this does not seem to be consistent with the intention of such schedules, and in general "catch-all" categories should not be included in such schedules.

Since most occupational disorders can also be caused by non-occupational exposures, the final decision on which disorders to include in a schedule should be based partly on the relative likelihood of a worker being exposed to the required occupational exposure circumstances. For this reason, a schedule should include an explicit identification that there 
must be "sufficient" exposure to the relevant exposure. Sufficient exposure in this context means exposure of sufficient duration and intensity that, based on current evidence, it is more likely than not to have contributed to the development of the condition. Relevant non-occupational exposures would not alter this. For example, persons with sufficient occupational exposure to an agent that is known to cause COPD should not be precluded from being covered by the schedule just because they smoke (even though smoking is also known to increase the risk of developing COPD).

The final content of a schedule must therefore be a balance between a restrictive approach, which will mean some workers with genuinely work-related illness will find it difficult to receive compensation, and a more inclusive approach, which runs the risk of some people receiving compensation for a disorder that is in fact not due to their occupation. As an example, the recommended format and content of the revised form of Schedule 2 in New Zealand is shown at Appendix A. Those disorders not recommended for inclusion, and the reasons for exclusion based on the three criteria presented earlier, are shown at Appendix B.

In conclusion, a list of occupational disorders to be used as a schedule for compensation purposes is best based primarily on a combination of specific disorder-exposure combinations. Criteria for inclusion can usefully cover strength of evidence, clear diagnostic criteria and the proportion of the cases of that disorder in the overall population or in an identifiable subset of the population.

\section{KEY POINTS}

Most current lists of compensable disorders are too broad to be useful as a schedule for fast-tracking claims.

Criteria to include disorders can usefully be based on strength of evidence, clear diagnostic criteria and population proportion.

Schedules are best based primarily on a combination of specific disorder-exposure combinations.

\section{FUNDING}

This work was supported by the National Occupational Health and Safety Advisory Committee (NOHSAC) at the request of the New Zealand Government.

\section{CONFLICT OF INTEREST}

None declared.

\section{ACKNOWLEDGEMENTS}

This paper is based on work conducted by the National Occupational Health and Safety Advisory Committee (NOHSAC) at the request of the New Zealand Government. The authors wish to thank the members of NOHSAC for their contribution to the project.

\section{AUTHORS' CONTRIBUTIONS}

All three authors were involved in developing the methodology for the project. Tim Driscoll conducted the main work and wrote the first draft of the manuscript. Mark Wagstaffe and Neil Pearce provided guidance and input during the project and provided comments on the manuscript.

APPENDIX A: Recommended format and content of Schedule 2 (New Zealand)

\begin{tabular}{|c|c|}
\hline Disorder & $\begin{array}{l}\text { Exposure or occupation } \\
\text { (sufficient occupational exposure required) }\end{array}$ \\
\hline \multicolumn{2}{|l|}{ Infectious disease } \\
\hline Anthrax & $\begin{array}{l}\text { Relevant occupations involving work with animals or animal carcasses (such as animal handler, pelt } \\
\text { handler, abattoir worker, meat inspector). }\end{array}$ \\
\hline Brucellosis & $\begin{array}{l}\text { Relevant occupations involving work with animals or animal carcasses (such as veterinarian, farmer or } \\
\text { farm worker, abattoir worker, laboratory worker). }\end{array}$ \\
\hline Hepatitis A & Relevant occupations involving contact with human waste (such as sewer worker, plumber). \\
\hline Hepatitis B and C & $\begin{array}{l}\text { Relevant occupations involving contact with human bodily secretions (such as health care worker, em- } \\
\text { balmer, person who handles body substances, clinical laboratory staff, worker in long-term correctional } \\
\text { facilities, police, member of the armed forces, emergency services worker). }\end{array}$ \\
\hline HIV/AIDS (and AIDS-related illnesses) & $\begin{array}{l}\text { Relevant occupations involving contact with human bodily secretions in situations where HIV preva- } \\
\text { lence is likely to be significantly higher than the general community (such as health care worker, sex } \\
\text { worker). }\end{array}$ \\
\hline Legionellosis & $\begin{array}{l}\text { Relevant occupations known to involve an increased risk of exposure to legionella species than in the } \\
\text { general community (such as air-conditioning maintenance worker, health care personnel, ship repair } \\
\text { worker, gardener, construction worker, sewerage worker, automotive plant worker, miner). }\end{array}$ \\
\hline Leptospirosis & $\begin{array}{l}\text { Relevant occupations involving work with animals or animal carcasses (such as farmer or farm worker, } \\
\text { abattoir worker, forestry worker, hunter, veterinarian, livestock transport operator) or work with animal } \\
\text { or human waste (such as plumber). }\end{array}$ \\
\hline Orf & $\begin{array}{l}\text { Relevant occupations involving work with sheep or sheep carcasses (such as sheep farmer or farm } \\
\text { worker, goat farmer or farm worker, abattoir worker, meat inspector). }\end{array}$ \\
\hline Streptococcus suis & $\begin{array}{l}\text { Relevant occupations involving work with pigs or pig carcasses (such as pig farmer or farm worker, pork } \\
\text { butcher, pig breeder, abattoir worker). }\end{array}$ \\
\hline Tuberculosis & $\begin{array}{l}\text { Relevant occupations involving contact with persons or animals in situations where tuberculosis preva- } \\
\text { lence is likely to be significantly higher than the general community (such as health worker, clinical } \\
\text { laboratory worker, funeral parlour staff, farmer, veterinarian), or person with silicosis. }\end{array}$ \\
\hline
\end{tabular}




\begin{tabular}{|c|c|}
\hline Disorder & $\begin{array}{l}\text { Exposure or occupation } \\
\text { (sufficient occupational exposure required) }\end{array}$ \\
\hline \multicolumn{2}{|l|}{ Malignancy } \\
\hline Liver cancer & Vinyl chloride monomer, persons with known $\mathrm{HBV}$ or $\mathrm{HCV}$ related to occupation \\
\hline Sino-nasal carcinoma & Wood dust \\
\hline Naso-pharyngeal carcinoma & Formaldehyde \\
\hline Larynx & Sulphuric acid mists, asbestos, organic solvents. \\
\hline Lung and bronchus & $\begin{array}{l}\text { Asbestos, arsenic, beryllium, bis-(chloro-methyl) ether (and chloromethyl methyl ether), cadmium, } \\
\text { chromium VI, coke oven emissions, diesel fumes, environmental tobacco smoke, nickel, radon, silica, } \\
\text { soot }\end{array}$ \\
\hline Skin (non-melanoma) & $\begin{array}{l}\text { Arsenic, polycyclic hydrocarbons (such as from tar, pitch, bitumen, mineral oil, shale oil, anthracene, or } \\
\text { other compounds, products, or residues of these substances); outdoor occupations }\end{array}$ \\
\hline Mesothelioma & Asbestos, erionite, talc containing asbestiform fibres \\
\hline Bladder cancer & $\begin{array}{l}\text { 2-naphthylamine, benzidine, 4-Aminobiphenyl, N,N-Bis(2-chloroethyl)-2-naphthylamine, other aromatic } \\
\text { amines, poly-cyclic aromatic hydrocarbons }\end{array}$ \\
\hline Hodgkin's lymphoma & Wood dust \\
\hline Non-Hodgkin's lymphoma & Phenoxyherbicides, chlorophenols, halogenated hydrocarbon solvents, dioxin \\
\hline Leukaemia & Ionising radiation, benzene, ethylene oxide \\
\hline Soft tissue sarcoma & Dioxin \\
\hline \multicolumn{2}{|l|}{ Disorders of the nervous system } \\
\hline Parkinson's disease & Manganese \\
\hline Peripheral neuropathy & $\begin{array}{l}\text { Metals such as lead, mercury and arsenic; organic solvents such as n-hexane, carbon disulphide and } \\
\text { trichloroethylene; pesticides such as organophophates; acrylamide. }\end{array}$ \\
\hline Chronic solvent-induced toxic encephalopathy & $\begin{array}{l}\text { Organic solvents, particularly styrene, toluene, xylene, trichloroethylene, tetrachloroethylene, methylene } \\
\text { chloride, white spirit }\end{array}$ \\
\hline \multicolumn{2}{|l|}{ Respiratory disorders (non-malignant) } \\
\hline Asthma ${ }^{1}$ & Sensitising agents or irritants both recognised in this regard and inherent in the work process. ${ }^{2}$ \\
\hline Byssinosis & Cotton, flax, hemp, sisal dust \\
\hline Extrinsic allergic alveolitis & Damp material of biological origin, such as mouldy hay, straw, grain and feathers \\
\hline Chronic obstructive pulmonary disease & Coal, silica, cotton or grain dust. \\
\hline Silicosis & Silica \\
\hline Asbestosis & Asbestos \\
\hline Coal workers' pneumoconiosis & Coal \\
\hline Other pneumoconiosis & $\begin{array}{l}\text { Exposures known to occasionally cause pneumoconiosis, such as beryllium, tin, iron oxide, barium, } \\
\text { aluminimum, cobalt, tungsten }{ }^{2}\end{array}$ \\
\hline \multicolumn{2}{|l|}{ Hepatic disorders } \\
\hline Chronic active hepatitis & Persons with known HBV or HCV related to occupation \\
\hline Hepatic cirrhosis & Persons with known HBV or HCV related to occupation \\
\hline Chronic renal failure & Metals such as lead, cadmium, chromium, copper and mercury, including via welding fumes \\
\hline \multicolumn{2}{|l|}{ Non-cancerous skin disorder } \\
\hline Contact dermatitis (irritant and allergic) & Sensitising agents or irritants both recognised in this regard and inherent in the work process. ${ }^{2}$ \\
\hline Occupational vitiligo & $\begin{array}{l}\text { Para-tertiary-butylphenol; para-tertiary-butylcatechol; para-amylphenol; hydroquinone or the monoben- } \\
\text { zyl or monobutyl ether of hydroquinone. }\end{array}$ \\
\hline
\end{tabular}


(Appendix A) Contd.....

\begin{tabular}{|c|c|}
\hline Disorder & $\begin{array}{l}\text { Exposure or occupation } \\
\text { (sufficient occupational exposure required) }\end{array}$ \\
\hline \multicolumn{2}{|l|}{ Musculoskeletal disorders } \\
\hline Rotator cuff syndrome & Repeated and/or sustained shoulder postures at greater than $60^{\circ}$ flexion or abduction \\
\hline Lateral epicondylitis & $\begin{array}{l}\text { Forceful and repetitive work involving wrist dorsiflexion, flexion, supination, and/or pronation, or that } \\
\text { exceeds ACGIH Hand TLV }\end{array}$ \\
\hline Medial epicondylitis & $\begin{array}{l}\text { Forceful and repetitive work involving wrist dorsiflexion, flexion, supination, and/or pronation, or that } \\
\text { exceeds ACGIH Hand TLV }\end{array}$ \\
\hline Ulnar nerve entrapment & Use of hand tools; working with raised arms; the combination of repetition, force and posture \\
\hline Radial nerve entrapment & Use of hand tools; working with raised arms; the combination of repetition, force and posture \\
\hline Tendonitis in the hand and fingers & Work involving highly repetitious, forceful hand/wrist exertions, or that exceeds ACGIH Hand TLV \\
\hline Raynaud's phenomenon & Vibration, hammer drills, hand-held portable grinders and jigsaws \\
\hline De Quervain's tenosynovitis & Use of hand tools; working with raised arms; the combination of repetition, force and posture \\
\hline Carpal tunnel syndrome & $\begin{array}{l}\text { Highly repetitive work, forceful work, and/or work involving exposure to vibration, or work that exceeds } \\
\text { ACGIH Hand TLV }\end{array}$ \\
\hline Bursitis (at the elbow or knee) & Prolonged external friction or pressure or repetitive motion at or about the elbow or the knee \\
\hline Noise induced hearing loss & Sufficient exposure to persistent or intermittent noise above $85 \mathrm{db}(\mathrm{a})$ \\
\hline $\begin{array}{l}\text { Acute poisoning / toxicity (includes acute } \\
\text { damage to the heart, lungs, liver, kidney, nerv- } \\
\text { ous system and blood) }\end{array}$ & $\begin{array}{l}\text { Acrylonitrile; alcohols; antimony; arsenic; benzene; beryllium; cadmium; carbon disulphide; chromium; } \\
\text { copper; fluorine; alcohol, glycols or ketones; hexane; lead; manganese; mercury; mineral acids; nitro- } \\
\text { glycerine (or other nitric acid esters); osmium; oxides of nitrogen; ozone; pesticides, herbicides and } \\
\text { related compounds; pharmaceutical agents; phosgene; phosphorus; selenium; styrene; thallium; tin; tolu- } \\
\text { ene; vanadium; zinc; chemical asphyxiants (carbon monoxide, hydrogen cyanide, hydrogen sulphide, } \\
\text { methylene chloride); irritants (benzoquinone and other corneal irritants); toxic halogen derivatives of } \\
\text { aliphatic or aromatic hydrocarbons; toxic nitro- and amino-derivatives of benzene }\end{array}$ \\
\hline
\end{tabular}

${ }^{1}$ Whether only immunologically-mediated asthma should be considered to be occupational asthma, or whether asthma arising as result of workplace exposure to irritants, or exacerbation of pre-existing asthma by workplace irritants, should also be considered in the definition, is still the subject of debate. However, the broader definition seems to currently be more widely accepted.

${ }^{2}$ The large number of occupational agents that have been shown to cause these disorders means that listing every relevant agent in connection with these disorders in Schedule 2 is impractical.

APPENDIX B: Disorders not recommended for inclusion in Schedule 2 (New Zealand), with justification against set criteria

\begin{tabular}{|c|c|}
\hline Disorder & Criteria not met by disorder ${ }^{1}$ \\
\hline \multicolumn{2}{|c|}{ Malignancy } \\
\hline Oral cavity cancer & Criteria 1 and 3 \\
\hline Colon cancer & Criteria 1 and 3 \\
\hline Rectal cancer & Criteria 1 and 3 \\
\hline Gall bladder cancer & Criteria 1 and 3 \\
\hline Pancreatic cancer & Criteria 1 and 3 \\
\hline Female breast cancer & Criteria 1 and 3 \\
\hline Cervical cancer & Criteria 1 and 3 \\
\hline
\end{tabular}


(Appendix B) Contd.....

\begin{tabular}{|c|c|}
\hline Disorder & Criteria not met by disorder ${ }^{1}$ \\
\hline Uterine cancer & Criteria 1 and 3 \\
\hline Prostate cancer & Criteria 1 and 3 \\
\hline Testicular cancer & Criteria 1 and 3 \\
\hline Brain cancer & Criteria 1 and 3 \\
\hline Myeloma & Criteria 1 and 3 \\
\hline Chemotherapeutic agents & Criterion 1 \\
\hline \multicolumn{2}{|c|}{ Vascular disorders } \\
\hline Ischaemic heart disease & Criterion 1 and 3 \\
\hline \multicolumn{2}{|c|}{ Musculoskeletal disorders } \\
\hline Occupational overuse syndrome & Criterion 1 and 2 \\
\hline Low back pain & Criteria 2 and 3 \\
\hline Osteoarthritis & Criteria 1 and 3 \\
\hline Scleroderma & Criteria 1 and 3 \\
\hline
\end{tabular}

${ }^{1}$ The criteria are as follows

1) There is strong evidence of causal link between the occupational exposure and the disorder;

2) There are clear and repeatable criteria for diagnosing the disorder; and

3) The disorder comprises a considerable proportion of the cases of that disorder in the overall population or in an identifiable subset of the population.

\section{REFERENCES}

[1] International Labour Organization. Meeting of Experts on the Revision of the List of Occupational Diseases (Recommendation No. 194). Geneva: ILO 2009.

[2] European schedule of occupational diseases. European Union, 2007. (Accessed February, 2010, at http://europa.eu/legislation_summaries/employment_and_social_po licy/health_hygiene_safety_at_work/c11112_en.htm)

[3] Labour Department. Guidance notes on the diagnosis of notifiable occupational diseases. Hong Kong: Labour Department 2006.

[4] Hauptverband der gewerblichen Berufsgenossenschaften. List of occupational diseases. In Bonn: HVBG 2002.

[5] Drummond A. A review of the Occupational Diseases Reporting System in the Republic of Ireland. Dublin: School of Public Health and Population Science 2007.

[6] Industrial Disease Standards Panel (Occupational Disease Panel). Report to the workers' compensation board on IDSP revisions to Schedule 3: phase one. Toronto: Workers' Compensation Board 1994.

[7] Institute for Occupational Health and Safety Development. List of occupational and compensable diseases. Manilla: IOHSAD; 1996.

[8] Department of Labour. Compensation for Occupational Injuries and Diseases Act, 1993 (No. 130 of 1993). Amendment of Schedule 3-2004. Department of Labour 2004.
[9] International Labour Organization. Identification and recognition of occupational diseases: Criteria for incorporating diseases in the ILO list of occupational diseases. Geneva: ILO 2009.

[10] Balmes J, Becklake M, Blanc P, et al. American Thoracic Society Statement: Occupational contribution to the burden of airway disease. Am Rev Resp Crit Care Med 2003; 167: 787-97.

[11] Lombardo L, Balmes J. Occupational asthma: a review. Environ Health Perspect 2000; 8: 697-704.

[12] Wagner G, Wegman D. Occupational asthma: prevention by definition. Am J Ind Med 1998; 33: 427-9.

[13] McNaughton H. The label 'Occupational Overuse Syndrome': time to change. N Z Med J 2000; 113: 193-4.

[14] Ruttenberg D, Walls C, Dryson E. 'OOS' and ergonomic considerations. N Z Med J 2000; 113: 404-5.

[15] Dryson E, Ogden J. Chronic organic solvent neurotoxicity: diagnostic criteria, in occupational safety and health information series. Wellington: Occup Health Saf 1998.

[16] Kaukiainen A, Hyvärinen H, Akila R, Sainio M. Symptoms of chronic solvent encephalopathy: euroquest questionnaire study. Neurotoxicology 2009; 30: 1187-94.

[17] Blanc P, Toren K. How much adult asthma can be attributed to occupational factors? Am J Ind Med 1999; 107: 580-7.

[18] Jeebhay M, Quirce S. Occupational asthma in the developing and industrialised world: a review. Int J Tuberc Lung Dis 2007; 11: 122-33.

[19] Agency for Toxic Substances and Disease Registry. ToxFAQs for chromium. Atlanta: ATSDR 2008. 
[20] Venables K, Chang-Yeung M. Occupational asthma. Lancet 1997; 349: 1465-9.

[21] Gawkrodger D. Occupational skin cancers. Occup Med 2004; 54: $458-63$.

Received: August 25, 2011

Revised: September 27, 2011

Accepted: September 29, 2011

(C) Driscoll et al.; Licensee Bentham Open.

This is an open access article licensed under the terms of the Creative Commons Attribution Non-Commercial License (http://creativecommons.org/licenses/by-nc/3.0/) which permits unrestricted, non-commercial use, distribution and reproduction in any medium, provided the work is properly cited.
Baan R, Grosse Y, Straif K, et al. A review of human carcinogensPart F: Chemical agents and related occupations. Lancet Oncol 2009; 10: 1143-4.

[23] Straif K, Baan R, Grosse Y, et al. Carcinogenicity of shift-work, painting, and fire-fighting. Lancet Oncol 2007; 8: 1065-6. 